\title{
8
}

\section{New Faculty Perceptions of Supervision and Mentoring: The Influence of Graduate School Experiences}

\author{
Shannon Gadbois \& Elizabeth Graham \\ Brandon University
}

This study examined new faculty members' perceptions and approaches to student supervision and mentoring as related to their own experiences as doctoral students. Previous research has examined the graduate student-supervisor/mentor relationship but has yet to examine its impact on subsequent graduate student practices when they enter academic positions. Fourteen Canadian faculty members participated in a study on the experiences and expectations of doctoral candidates and early career academics. As a group, these new faculty members perceived that ideally a supervisor would also be a mentor. They perceived that a mentor shares professional and personal experience, functions as a sounding board,' provides guidance and advice, and helps prepare students for the work they are currently doing and for their career responsibilities in the future. A majority of these new faculty members reported that their graduate supervisors were not their only mentor or did not function as a mentor. Furthermore, all participants reported that they consciously made an effort to include mentorship as part of their supervisory role. These findings indicated that graduate students' own experiences of being supervised andlor mentored informed approaches with their own students. This research shows the apparent value in studying the influences of these important graduate school relationships and demonstrates the way in which our perspectives on supervisory relationships may influence subsequent practice.

$\mathrm{n}$ the academic profession, mentoring
relationships have been given considerable attention. Researchers (e.g., Kram, 1983; Paglis, Green, \& Bauer, 2006) have specified particular functions of mentors including the often informal influence on the development of self-confidence, to the more formal development of career skills needed within the profession. Specifically, Weidman and Stein (2003) argued that doctoral students acquire essential professional skills when their faculty members in their programs promote and encourage scholarly activities on a daily basis. In fact, researchers 
(e.g., Baker \& Pifer, 2011; Schor, 2003; Schrodt, Cawyer, \& Sanders, 2003; Sorcinelli \& Yun, 2007) have noted proactive and supportive mentors are vital to subsequent success in the academic context. The impact of the relationship between students and their supervisors and/or mentors can mean the difference between pursuing an academic career or not doing so (e.g., Singer, Cassin, \& Dobson, 2005). Consistent with this idea, Paglis et al. (2006) longitudinal study showed that doctoral candidates whose advisors provided psychosocial mentoring (i.e., helped students develop a sense of competence in their work) and research collaborative mentoring (i.e., working with students on shared publications) showed greater research self-efficacy and research productivity in subsequent years of their studies.

Research has also shown that graduate programs are not effective in preparing graduates for their roles in part because many graduate supervisors are not necessarily mentors, although students expect they will be (e.g., Austin, 2002; Gadbois \& Graham, 2009; Manathunga, 2007). Adams (2002) argued that students want mentorship that encompasses more than research skills training. Specifically, Adams proposed that graduate advisors should be helping their students develop the necessary skills so that they themselves will become effective student supervisors and mentors. In fact, although research has focused on the graduate studentsupervisor/mentor relationship, it is important to consider how this relationship might influence new student-supervisor/mentor relationships (e.g., Bean, Readence, Barone, \& Sylvester, 2004). As such, exploring the experiences of new academics should be beneficial given the importance of mentoring relationships for students, and the lack of formal preparation academics receive in relation to their potential roles as mentors.

Because new academics have just completed school, they can offer a unique and useful source of data specifically with reference to their experiences and insights regarding supervision and mentorship of their own students and based on their own experiences as students. Furthermore, education researchers (e.g., Erden, 2009) have emphasized that our beliefs about learning and teaching are the filters through which we determine our instructional practices and interactions with students, including mentoring students. In keeping with these ideas, our primary goal was to examine the experiences of early career academics regarding their ideas and practices as supervisors and/or mentors and the similarities and differences between their experiences with their doctoral supervisors and their approaches with their own students.

\section{Methodology}

Fourteen Canadian academics (three men and 11 women), within the first five years of their positions, volunteered to participate in our study of the expectations and experiences of doctoral students and early career academics. As a group, they were employed across five provinces and in a range of disciplines (e.g., political science, anthropology, sociology, psychology) in both primarily undergraduate and comprehensive universities. In the first part of the study, participants completed an online survey. Those who wished to participate in an interview contacted the first or second author. Almost all of our early career academic interview participants $(n=13)$ were assistant professors in tenure track positions.

All participants completed individual, semistructured interviews. Although they answered a broad range of questions regarding their experiences in graduate studies and in their current position, this paper examines the most common participant responses with respect to: the essential characteristics of a mentor relationship, the relationship between supervision and mentorship, their experiences with their own supervisor, and the similarities and differences between their own and their supervisors' approaches.

\section{Results}

First, the participants' conceptualizations of mentorship were generally consistent in that they all emphasized that a mentor should provide both professional and personal support to her/his mentee. 
As one participant explained:

"A good mentor...makes sure that the student is not only doing the... narrow dictates of what the program requires, but is emotionally on track... It's not just... 'are you reading these books and getting these chapters done' but 'how are you coping' on a personal level" (Interviewee 1).

More specifically, participants indicated that a mentor provides guidance and advice sharing information regarding their own career struggles, successes, and failures. The importance of advice and sharing indicated in the following statements is reflective of the thoughts many participants expressed:

"Provides advice if...you're struggling with something...shares their personal experiences with you" (Interviewee 2).

"A mentor is someone who shares their past discoveries with you...in a way that might hopefully offer you some markers along this sort of new road that you're on" (Interviewee 13).

Almost every participant particularly emphasized that a mentor provides guidance. Some participants more specifically discussed certain dimensions of guidance when describing a mentor:

"I guess just provides guidance, I suppose like in terms of teaching or research... and I guess... maybe about the politics of the university, and the politics of getting published, and so on" (Interviewee 3).

Previous research (e.g., Rose, 2005) has emphasized the importance of mentorship guidance as related to doctoral student satisfaction.

Across the 14 interviewees only one believed that a doctoral student could successfully complete their studies without having a mentor, although this individual did indicate that not having a mentor would make the process very difficult. Importantly, when specifically asked, all of the interviewees stated that a supervisor should also be a mentor. This finding, consistent with other research (Austin, 2002), is significant given that only three of the 14 interviewees stated that their supervisor was their mentor.

Second, participants were asked about how their approach to supervision was similar to or different from their supervisors' approaches. Of the participants, nine individuals had already supervised students. Only one indicated that she consciously and specifically modelled the approaches of her graduate supervisor. In contrast, the remaining participants indicated that although they did often follow their supervisors' approaches with regard to promoting academic skills development, unlike their own supervisors, they tried to provide psychosocial support for their students. They specifically reported trying to combine mentorship and supervision in their work with students. The comments from Interviewees 9 and 10 particularly reflect this fact:

"I do find myself doing a lot of the same things that he did...I guess the one thing I do a little bit differently is...I think I'm a lot more...I guess I know my students a lot more on a personal level than he did...My students don't see me as their friend, but they see me as very friendly and we have a pleasant relationship" (Interviewee 9).

"You don't have to dive too deep into their personal life, but to have a certain idea of their personal life and what's going on outside the academic world. I thought this was something important that I didn't get when I was in graduate studies...seeing the student as more as a person as opposed to just somebody working on a 
thesis I think would be an important point" (Interviewee 10).

These new faculty members specifically indicated that they were trying to include in their supervisory practices what was missing in their experiences with their own supervisors, again emphasizing the importance of psychosocial support. Two interviewees stated:

"I try to convey the experience that I have to my students...so that they don't have to go through it on their own...I try to make myself human and approachable" (Interviewee 5).

"You could choose the most brilliant scholar in your field to be your supervisor but that person could actually be a lousy mentor...you could end up with the world's best dissertation and absolutely no professional skills...I try to be a mentor. I feel like that's definitely a responsibility that I have" (Interviewee 6).

In fact, at least one study (Lechuga, 2011) showed that faculty members who mentored their graduate students, emphasized that their responsibilities included both professional and personal support.

\section{Discussion}

Consistent with views from other levels of educational training, it makes sense that the perspectives we hold regarding how we should teach should influence what we actually do. In this study, we were interested in the graduate school experiences of early career academics and how these experiences were related to their ideas of supervision and mentorship. Generally, the results showed that the participants believed that they did not receive both supervision and mentorship from their graduate supervisors although they believed that a supervisor should also be a mentor. More specifically, as a group, these new faculty members perceived their supervisors provided good professional mentorship though they did not provide sufficient psychosocial mentorship. Related to this fact is that those who had already supervised their students reported that they particularly made an effort to provide psychosocial supports for their own students.

These findings are consistent with other research (e.g., Rose, 2005) that shows graduate students' beliefs in the importance of both professional and psychosocial mentorship. These findings are also consistent with research that shows that some students particularly desire or need psychosocial mentorship (e.g., Bell-Ellison \& Dedrick, 2008). Furthermore, consistent with at least one paper (Bean et al., 2004), our findings extend this work and show that students' experiences with their own graduate supervisors seem to inform and influence their subsequent interactions with their own students. Importantly, our participants reported that they made a conscious effort to draw upon their prior experiences in considering their own roles as supervisors. These findings are important given research (e.g., Bernier, Larose, \& Soucy, 2005) that has indicated that effective mentoring arises when faculty members pay attention to the way in which they interact with students.

Though these outcomes complement the literature on graduate student supervision and mentorship it is important to note some limitations of this research that might be overcome in future studies. First, our sample consisted of early career academics almost all of whom were in tenure-track academic positions. That is, by definition, they are likely to have been successfully mentored with regard to career skills and may have had more positive experiences in general in their interactions with their supervisors compared to the broader pool of doctoral candidates in Canada. Second, although our participants talked about how they tried to supervisor and mentor their students, we have no way of knowing whether, in fact, they were successful in doing so. Similarly, we had no means of determining whether their graduate supervisors believed that they were providing both career and psychosocial support, or whether any of their supervisors were recent graduates themselves. 
Finally, some of our participants had not had an opportunity to supervisor students. However, even these participants did specifically state that they would attempt to supervise and mentor their students while being mindful of both academic and psychosocial support. That is, their proposed approaches were consistent with the individuals who had already supervised students.

This research demonstrates the there is merit in exploring the student-supervisor/mentor relationship beyond graduate training to consider the potential influences on subsequent practice of academics. It also implies that even better studentsupervisor mentoring relationships may evolve from those that are successful at least in career development. Ideally, future research would include a more detailed examination of both sides (i.e., graduate student and supervisors) of the relationship (perhaps over time) as graduate students' progress from mentee to mentor.

\section{References}

Adams, K.A. (2002). What colleges and university want in new faculty. Washington, DC: Association of American Colleges and Universities. Retrieved from http://www. aacu.org/pff/ pdfs/PFF_Adams.PDF

Austin, A.E. (2002). Preparing the next generation of faculty: Graduate school as socialization to the academic career. The Journal of Higher Education, 73(1), 94-122.

Baker, V.L. \& Pifer, M.J. (2011). The role of relationships in the transition from doctoral student to independent scholar. Studies in Continuing Education, 33(1), 5-17.

Bean, T.W., Readence, J.E., Barone, D.M., \& Sylvester, T. (2004). An interpretive study of doctoral mentoring in literacy. Mentoring and Tutoring, 12(3), 371-381.

Bell-Ellison, B.A. \& Dedrick, R.F. (2008). What do doctoral students value in their ideal mentor?
Research in Higher Education, 49, 555-567.

Bernier, A., Larose, S., \& Soucy, N. (2005). Academic mentoring in college: The interactive role of student's and mentor's interpersonal dispositions. Research in Higher Education, 46(1), 29-51.

Erden, F.T. (2009). A course on gender equity in education: Does it affect gender role attitudes of preservice teachers? Teaching and Teacher Education, 25, 409-414.

Gadbois, S.A. \& Graham, E. (2009, August). Doctoral students' perceptions: Are supervisors good mentors? Poster presentation at the American Psychological Association Annual Conference, Toronto, Ontario.

Kram, K. (1983). Phases of the mentor relationship. Academy of Management Journal, 26(4), 608-625.

Lechuga, V.M. (2011). Faculty-graduate student mentoring relationships: Mentors' perceived roles and responsibilities. Higher Education, 62, 757-771.

Manathunga, C. (2007). Supervision as mentoring: The role of power and boundary crossing. Studies in Continuing Education, 29(2), 207221.

Paglis, L.L., Green, S.G., \& Bauer, T.N. (2006). Does adviser mentoring add value? A longitudinal study of mentoring and doctoral student outcomes. Research in Higher Education, 47(4), 451-476.

Rose, G.L. (2005). Group differences in graduate students' concepts of the ideal mentor. Research in Higher Education, 46(1), 53-80.

Schor, N.F. (2003). The supportive academic environment: Ingredients for success. Pediatric Neurology, 29(5), 370-373. 
Schrodt, P., Cawyer, C.S., \& Sanders, R. (2003). An examination of academic mentoring behaviours and new faculty members' satisfaction with socialization and tenure and promotions processes. Communication Education, 52(1), 17-29.

Sorcinelli, M.D. \& Yun, J. (2007). From mentoring to mentoring networks: Mentoring in the new academy. Change, 39(6), 58-61.

Singer, A.R., Cassin, S.E., \& Dobson, K.S. (2005). The role of gender in the career aspirations of professional psychology graduates: Are there more similarities than differences? Canadian Psychology, 46, 215-222.

Weidman, J.C. \& Stein, E.L. (2003). Socialization of doctoral students to academic norms. Research in Higher Education, 44(6), 641-656.

\section{Biographies}

Shannon Gadbois, an Associate Professor in the Department of Psychology at Brandon University, conducts research on extracurricular activities participation and positive youth development, university students' learning and performance, and gender issues in academia.

Elizabeth Graham, an Assistant Professor in the Departments of Sociology and Gender and Women's Studies at Brandon University, conducts research on sense of Self, autonomy, and their interconnection with the social context. 